\title{
BMJ Open Interpregnancy weight change and adverse pregnancy outcomes: a systematic review and meta-analysis
}

\author{
Eugene Oteng-Ntim, ${ }^{1}$ Sofia Mononen, ${ }^{2}$ Olga Sawicki, ${ }^{1}$ Paul T Seed, ${ }^{2}$ Debra Bick, ${ }^{2}$ \\ Lucilla Poston ${ }^{2,3}$
}

To cite: Oteng-Ntim E, Mononen S, Sawicki 0, et al. Interpregnancy weight change and adverse pregnancy outcomes: a systematic review and meta-analysis. BMJ Open 2018;8:e018778. doi:10.1136/ bmjopen-2017-018778

- Prepublication history and additional material for this paper are available online. To view these files, please visit the journal online (http://dx.doi. org/10.1136/bmjopen-2017018778).

Received 20 July 2017 Revised 10 April 2018 Accepted 16 April 2018

Check for updates

${ }^{1}$ London School of Hygiene and Tropical Medicine, London, UK ${ }^{2}$ Department of Women and Children's Health, King's College, London, UK

${ }^{3}$ Women's and children, King's College London, London,

England, United Kingdom

\section{Correspondence to}

Dr Eugene Oteng-Ntim Dr; Eugene.oteng-ntim@gstt.nhs.uk and prof. Lucilla Poston;

Eugene.oteng-ntim@gstt.nhs.uk

\section{ABSTRACT}

Objectives To evaluate the effect of interpregnancy body mass index (BMI) change on pregnancy outcomes, including large-for-gestational-age babies (LGA), small-for-gestationalage babies (SGA), macrosomia, gestational diabetes mellitus (GDM) and caesarean section (CS).

Design Systematic review and meta-analysis of observational cohort studies.

Data sources Literature searches were performed across Cochrane, MEDLINE, EMBASE, CINAHL, Global Health and MIDIRS databases.

Study selection Observational cohort studies with participants parity from 0 to 1 .

Main outcome measures Adjusted ORs (aORs) with $95 \%$ Cls were used to evaluate the association between interpregnancy BMl change on five outcomes.

Results 925065 women with singleton births from parity 0 to 1 were included in the meta-analysis of 11 studies selected from 924 identified studies. A substantial increase in interpregnancy BMI (>3 BMl units) was associated with an increased risk of LGA (aOR 1.85, 95\% $\mathrm{Cl} 1.71$ to 2.00, $\mathrm{p}<0.001$ ), GDM (aOR 2.28, 95\% $\mathrm{Cl} 1.97$ to $2.63, \mathrm{p}<0.001$ ), macrosomia (aOR 1.54, $95 \% \mathrm{Cl} 0.939$ to 2.505 ) and CS (aOR 1.72, 95\% Cl 1.32 to 2.24, $\mathrm{p}<0.001$ ) compared with the reference category, and a decreased risk of SGA (aOR $0.83,95 \% \mathrm{Cl} 0.70$ to $0.99, \mathrm{p}=0.044)$. An interpregnancy BMl decrease was associated with a decreased risk of LGA births (aOR $0.70,95 \% \mathrm{Cl} 0.55$ to $0.90, \mathrm{p}<0.001$ ) and GDM (aOR $0.80,95 \% \mathrm{Cl} 0.62$ to 1.03 ), and an increased risk of SGA (aOR $1.31,95 \% \mathrm{Cl} 1.06$ to $1.63, \mathrm{p}=0.014)$. Women with a normal BMI $\left(<25 \mathrm{~kg} / \mathrm{m}^{2}\right)$ at first pregnancy who have a substantial increase in BMI between pregnancies had a higher risk of LGA (aOR 2.10, 95\% Cl 1.93 to 2.29) and GDM (aOR 3.10, $95 \% \mathrm{Cl} 2.74$ to 3.50 ) when compared with a reference than women with a $\mathrm{BMl} \geq 25 \mathrm{~kg} / \mathrm{m}^{2}$ at first pregnancy.

Conclusions Gaining weight between pregnancies increases risk of developing GDM, CS and LGA, and reduces risk of SGA in the subsequent pregnancy. Losing weight between pregnancies reduces risk of GDM and LGA and increases risk of SGA. Weight stability between first and second pregnancy is advised in order to reduce risk of adverse outcomes. Trial registration number CRD42016041299.

\section{INTRODUCTION}

The associations between high pregravid body mass index (BMI) and maternal and neonatal complications are well established ${ }^{1}$;

\section{Strengths and limitations of this study}

- We believe this to be the first meta-analysis completed on the topic of interpregnancy weight change and its effect on five adverse pregnancy outcomes.

- A large sample size of 925065 women was collected from 11 well-adjusted population-based observational studies, with two methods used to assess the quality of the studies.

- Sensitivity analysis was conducted to remove low-quality research, which did not change the direction of effect for any outcome.

- Limitations included limited generalisability, as the research was conducted in high-income countries and only in women from parity 0 to 1 .

- Furthermore, high heterogeneity persisted after sensitivity analysis, and additional confounders (such as breast feeding) could affect the results.

complications include gestational diabetes mellitus (GDM), caesarean section (CS), pre-eclampsia, macrosomia, prematurity and stillbirth. ${ }^{2}$ These outcomes are of public health importance because they add to the disease burden of women and their infants,thereby increasing healthcare costs. ${ }^{3}$ Mirroring the trend of the global obesity epidemic (more than half of all women of reproductive age in the UK are overweight or obese), ${ }^{4}$ the prevalence of all these pregnancy complications has risen, as has the focus on maternal weight management as a means to improve the health of women and their children.

Previous studies have investigated the effect and impact of increased weight on adverse outcomes at all stages of the periconceptional period. ${ }^{5}$ Lifestyle and medical interventions during pregnancy have shown little effect on pregnancy outcomes. ${ }^{6}$ In the meantime, interpregnancy care is aimed at optimising outcomes of women and their future babies. But standards are lacking ${ }^{8}$ and, owing to the paucity of literature, systematic reviews and 
Table 1 Definitions of maternal and fetal outcomes used throughout this review

\begin{tabular}{|c|c|}
\hline Outcome & Definition \\
\hline $\begin{array}{l}\text { Large for gestational } \\
\text { age }\end{array}$ & $\begin{array}{l}\text { A baby with birth weight } \geq 90 \text { th } \\
\text { percentile of all babies with same } \\
\text { gestational age. }{ }^{2}\end{array}$ \\
\hline $\begin{array}{l}\text { Small for gestational } \\
\text { age }\end{array}$ & $\begin{array}{l}\text { A baby with birth weight }<10 \text { th } \\
\text { percentile of all babies with same } \\
\text { gestational age. }{ }^{2}\end{array}$ \\
\hline Macrosomia & Birth weight of $>4000 \mathrm{~g}^{50}$ \\
\hline Caesarean section & $\begin{array}{l}\text { Surgical incision into abdominal and } \\
\text { uterine wall to achieve delivery of } \\
\text { the baby. }{ }^{51} \text { Only emergency CS was } \\
\text { considered in this study. }\end{array}$ \\
\hline $\begin{array}{l}\text { Gestational diabetes } \\
\text { mellitus }\end{array}$ & $\begin{array}{l}\text { Any degree of glucose intolerance } \\
\text { with onset or first recognition during } \\
\text { pregnancy. }\end{array}$ \\
\hline
\end{tabular}

meta-analysis, any effect of interpregnancy care on pregnancy outcomes remains nascent. ${ }^{8-10}$

Despite a plausible rationale for weight management as part of interpregnancy planning, a knowledge gap exists among healthcare providers and women of reproductive age of the impact of weight change between pregnancies. Interpregnancy weight change is defined as the difference in BMI between first and second pregnancy recorded at the first antenatal visit. ${ }^{11}$ While the number of relevant studies has expanded in recent years, no meta-analysis has been attempted. The aim of this meta-analysis was to address this gap by examining the association between interpregnancy weight change and the most prevalent associated adverse pregnancy outcomes: GDM, CS, large-for-gestational-age babies (LGA) and small-for-gestational-age babies (SGA) in the next pregnancy (see table 1 for definitions). Where possible, the data were divided according to maternal $\mathrm{BMI}<25$ and $\geq 25 \mathrm{~kg}$ / $\mathrm{m}^{2}$, in order to address effects of interpregnancy weight change in the overweight/obese population compared with women with a normal BMI. Only the first two successive pregnancies were assessed in order to minimise confounding due to any effects of parity on pregnancy outcome.

\section{METHODS}

\section{Protocol and registration}

The study was registered in The International Prospective Register of Systematic Reviews (PROSPERO) (CRD42016041299). The criteria outlined in the Preferred Reporting Items for Systematic Reviews and Meta-Analyses (PRISMA) statement and the Meta-analysis of Observational Studies in Epidemiology (MOOSE) checklist was adhered to.

\section{Information sources}

Electronic databases including CINAHL, EMBASE, MEDLINE, the Cochrane Database of Systematic Reviews,
Table 2 Search strategy for MEDLINE

1 exp birth intervals/

2 (interpregnan* or inter-pregnan* or (birth adj interval) or (between adj pregnan*) or (successive adj pregnan*) or interbirth or (pregnan* adj spacing) or (pregnan* adj interval) or (birth adj spacing) or interdelivery or (consecutive adj pregnan*) or (following adj pregnanc*) or (subsequent adj pregnan*)).mp.

\section{1 or 2}

4 ((body adj weight) or body mass index or BMI or (weight adj change) or (weight adj los*) or (weight adj decrease) or (weight adj gain*) or (weight adj increase) or (BMI adj change) or (body adj mass adj index) or (body adj weight adj change)).mp.

5 ((pregnancy adj complication) or (f?etal adj outcome) or (pregnancy adj outcome) or (adverse adj outcome) or macrosomia or large for gestational age or LGA or large-for-gestational-age or (birth adj weight) or SGA or small for gestational age or small-for-gestational-age or GDM or (gestational adj diabetes) or c-section or (c?esarean adj section).mp.

$6 \quad 3$ and 4 and 5

7 Limit 6 to humans

MIDIRS and Global Health were searched from January 1990 to January 2017. Searches were limited to studies in humans. There were no language constraints. In addition, references from bibliographies and citations were manually searched. A grey literature search was run until 1 January 2017 across the following clinical trials registries: TRIP Database, EThOS, WHO International Clinical Trials Registry Platform Search Portal and the EU Clinical Trials Register.

\section{Search strategy}

A search strategy was developed for MEDLINE (see table 2) and adapted for other databases. The following combination of MeSH terms and free text were used: interpregnancy, prepregnancy, weight gain, weight loss, neonatal outcomes and pregnancy complications.

\section{Outcome measures}

Five of the most prevalent adverse outcomes were chosen as outcomes of interest for this review. These included LGA, SGA, macrosomia, CS and GDM (defined in table 1). Gender-specific birth weight charts were used in the research for LGA and SGA birth weights. It should be noted that throughout this paper, BMI will be referred to in groups according to the WHO and National Institute for Health and Care Excellence (NICE) BMI classifications. ${ }^{12}$

\section{Study selection}

Observational studies such as cohort and case-control studies were included, with studies limited to humans. Only singleton births from parity 0 to 1 were included. Studies that were restricted to women with previous diabetes diagnoses were excluded, as were studies 
published as conference abstracts, reviews, pharmacological or surgical interventions for weight loss, case reports or unpublished trials. Citations found through database searches and other searches such as browsing bibliographies were combined and duplicates excluded.

\section{Data collection and extraction}

The Cochrane Good Practice Data Extraction Form was used for extracting relevant data of each study. Raw data were collected where available or calculated from the information given. Adjusted ORs (aORs) and 95\% CIs were extracted from all papers. Additional information collected from studies included: first author's name and year of publication, study design, setting, study period, sample size, outcomes, inclusion/exclusion criteria, quality assessment and population demographics and factors that each study adjusted for (including age, race, socioeconomic status, interpregnancy interval, previous maternal disease, gestational weight gain and education level).

To study whether association between change in body weight and adverse outcomes differed, study groups were classified as 'substantial increase in BMI', 'moderate increase in BMI' and 'decrease in BMI'. These groups were defined as BMI increase of $>3$ units (substantial increase), BMI increase between 1 and 3 units (moderate increase) and BMI decrease $>1$ unit (decrease). If an outcome had small number of studies, substantial increase and moderate increase were combined as 'increase in BMI'. In studies that reported results based on the WHO classification, women who changed from normal weight to underweight were considered as part of the BMI decrease category, and weight change from normal to obese represented a substantial increase in BMI. These studies were used as part of subgroup analyses (initial BMI $>25 \mathrm{~kg} /$ $\mathrm{m}^{2}$ 'overweight/obese' or BMI $<25 \mathrm{~kg} / \mathrm{m}^{2}$ 'normal') and converted into substantial (normal to obese), moderate (normal to overweight) and decrease in BMI groups (normal to underweight), respectively.

Interpregnancy weight change was defined as the prepregnancy BMI before first pregnancy to the prepregnancy BMI before second pregnancy. For each outcome, the association of BMI change on adverse pregnancy outcome was compared with the reference category, which was defined as women who remained within their BMI category or their BMI changed by up to 2 units in either direction.

Two investigators (SM, OS) independently performed the literature search, assessed the eligibility and quality of the retrieved papers and performed the data extraction. The two authors compared the results and disagreements were resolved by a third reviewer (EO-N).

\section{Risk of bias assessment}

To assess the quality of the studies, a modified Newcastle-Ottawa Scale (NOS) and a Cochrane analysis of bias were performed. Sensitivity analysis was performed by removing studies with a NOS score ( $\leq 4$ stars) or a high level of bias ( $<3$ points) according to the Cochrane analysis.

\section{Statistical analysis}

Forest plots were made for each outcome to assess overall effect size and heterogeneity using Stata SE V.14 (StataCorp, College Station, Texas, USA). Random-effects model was used to account for variability across studies. Study weight was calculated using the inverse variance method. Data were pooled and heterogeneity assessed with the $\mathrm{I}^{2}$ statistic, with a high heterogeneity defined as being over $50 \%$. Results were considered statistically significant if $p$ value was $<0.05$. Sensitivity analysis was performed by removing low-quality studies. Analysis was then repeated and results compared.

\section{Role of funding source}

The funders had no role in study design, data collection, data analysis, data interpretation or writing of the report. The authors had full access to all data in the study and had final responsibility for the decision to submit for publication.

\section{Patient and public involvement}

No patients were involved in setting the research question or the outcome measures, and no patients were involved in developing plans for design or implementation of the study. Furthermore, no patients were asked to advice on interpretation or writing up of results. Since this meta-analysis used aggregated data from previous trials, it is unable to disseminate the results of the research to study participants directly.

\section{RESULTS}

\section{Literature search results}

Results from the literature search came back with 11 studies to be included in the qualitative synthesis. The 2009 PRISMA flow diagram can be seen in figure 1, showing the process of study selection.

\section{Study characteristics}

Study characteristics can be found in table 3. Out of the studies, one study was from Belgium, ${ }^{13}$ seven were from the USA, ${ }^{14-20}$ two from Scotland ${ }^{21} 22$ and one from Sweden. ${ }^{23}$ Four papers studied GDM, five papers studied LGA, four papers studied SGA, one paper studied macrosomia and six papers studied CS (table 3). All studies presented their data in aORs. Seven out of the 11 studies used self-reports to record prepregnancy weight and height. All studies adjusted for confounding variables such as age, race, education and marital status with most studies also adjusting for interpregnancy interval, smoking, socioeconomic status, alcohol use, country of birth and maternal illness. About half of the prospective studies were community-based, using data found from national or state databases while other studies used hospital data. 


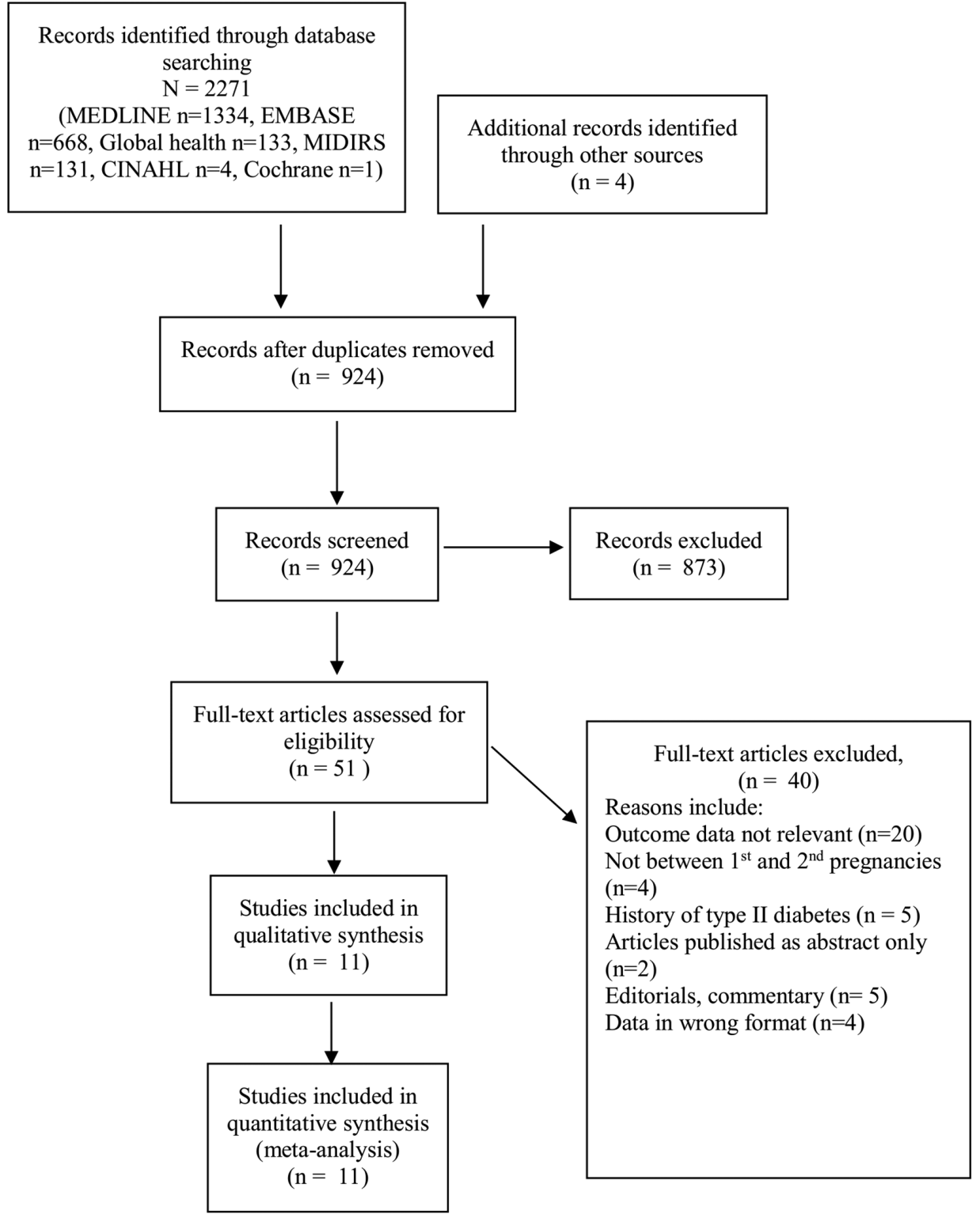

Figure 1 The 2009 Preferred Reporting Items for Systematic Reviews and Meta-Analyses flow diagram showing results of literature search.

\section{Data quality}

Data quality was assessed using a modified $\operatorname{NOS}^{24}$ as well as a Cochrane tool of assessing bias in studies. ${ }^{25}$ The criteria for allocating stars (out of a total of 7 stars) awarded to each study according to this NOS criteria can be found in online supplementary appendix table 1 . The results of these data quality assessment can be seen in online supplementary appendix 1, tables 2-3. The exposed cohort was defined as women with a change in interpregnancy BMI, while the non-exposed cohort was defined as women who remained within their original BMI category or their BMI changed by up to 2 units in either direction. Despite authors attempting to adjust for the missing data, only five studies assessed the problem of missing data and analysed if this missing data were significant. One study ${ }^{13}$ did not report data unless it was statistically significant, giving rise to a possible high risk of reporting bias. Self-reported assessment of exposure as well as incomplete data are the two greatest sources of bias in the studies. The total score shown in online supplementary appendix 1, table 3 allows for comparison of Cochrane analysis of bias and NOS. These two assessments show good agreement; good quality studies tended to have a lower risk of bias.

\section{Outcomes}

A decrease in BMI ( $>1$ BMI unit) was associated with a $33 \%$ reduction in LGA births (aOR $0.70,95 \%$ CI 0.55 to $0.90, \mathrm{I}^{2}=82.0 \%$ ), while a moderate increase in BMI is associated with a $43 \%$ higher risk of LGA birth compared with the reference category (aOR $1.43,95 \%$ CI 1.29 to 1.59 , $\mathrm{I}^{2}=57.4 \%$ ). A significant increase in BMI, defined as being an increase of over 3 units, had the highest risk of LGA birth (aOR $1.85,95 \%$ CI 1.71 to $2.00, \mathrm{I}^{2}=0 \%$ ) (figure 2 ). $\mathrm{Z}$-values and $\mathrm{p}$ values for these results (see online 


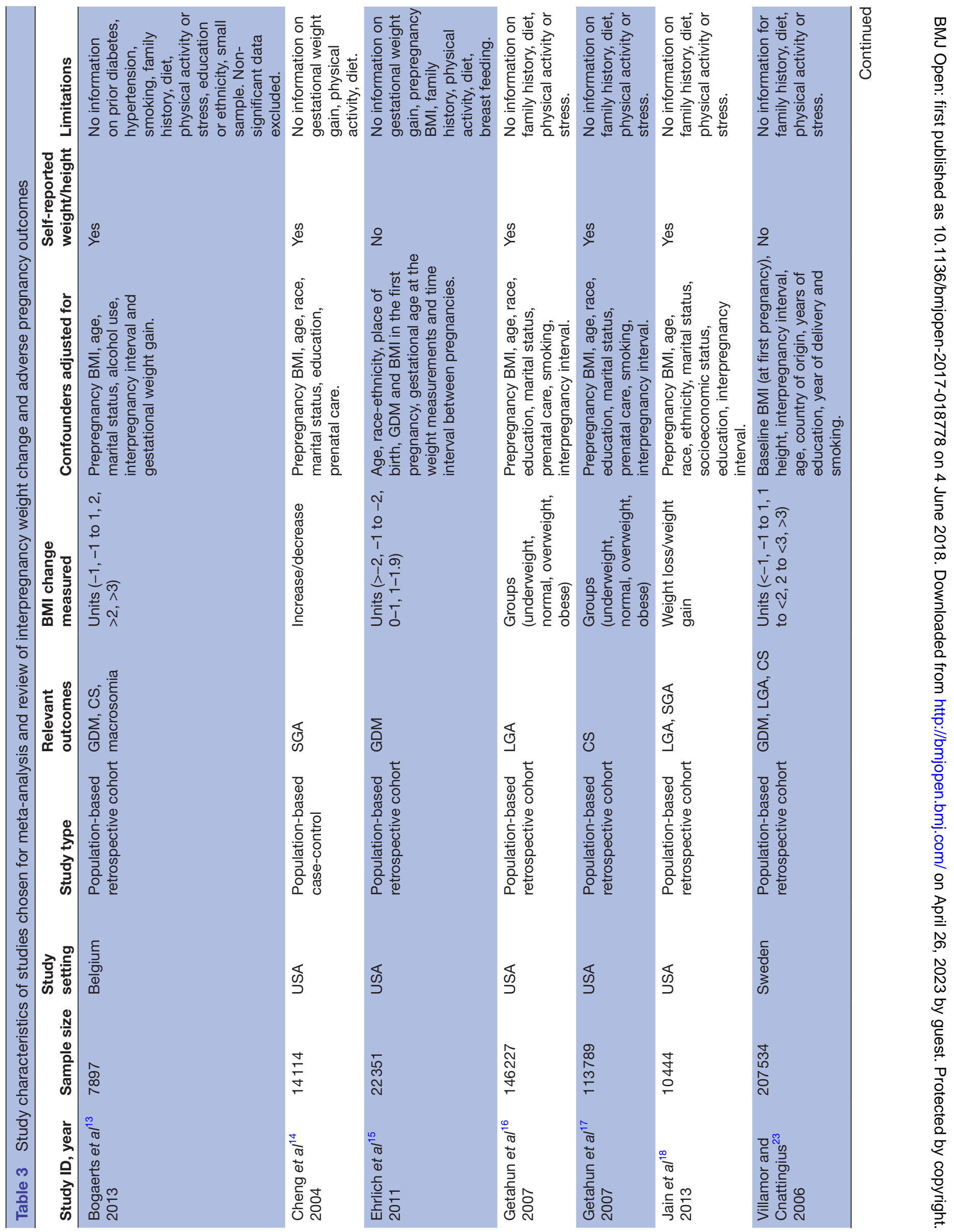




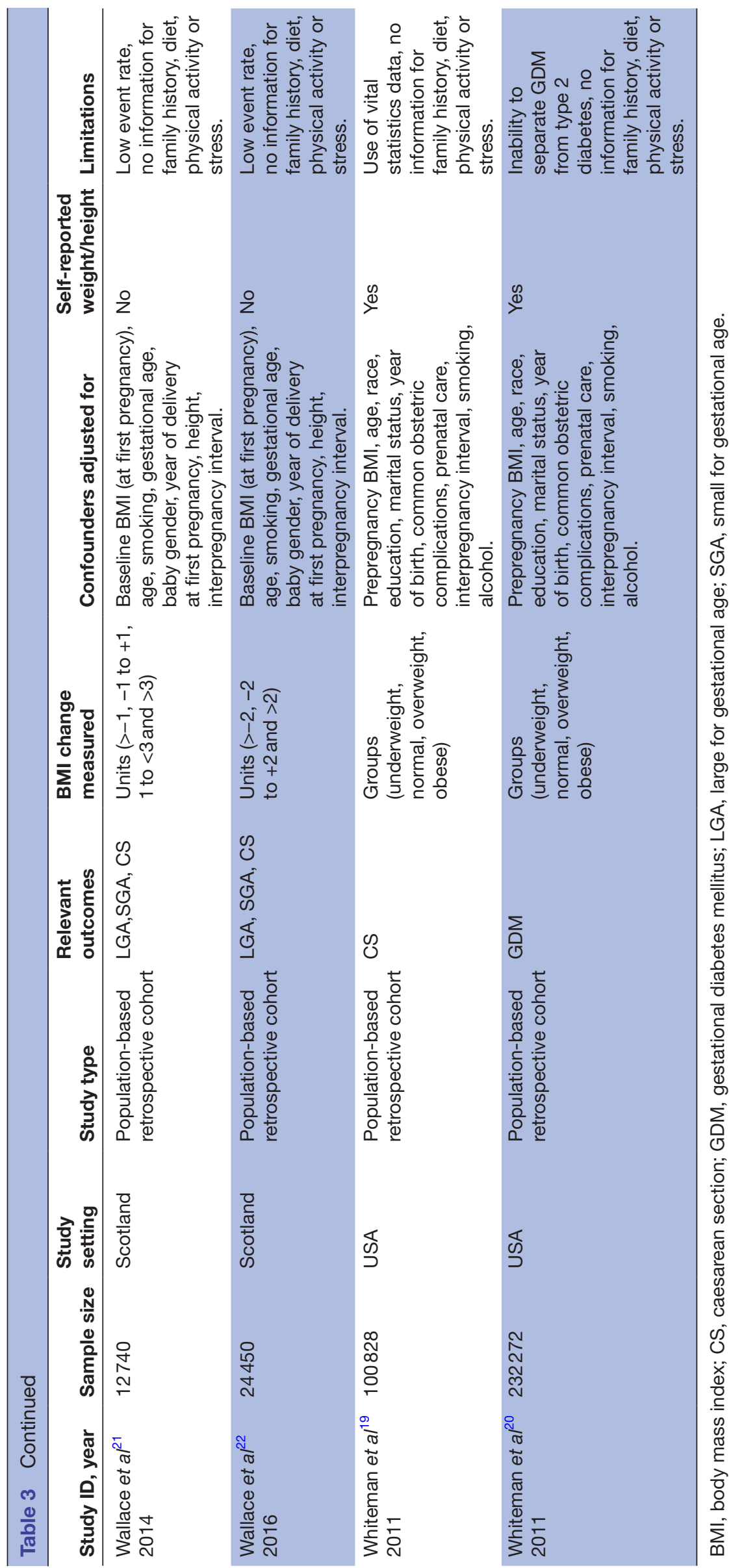




\section{Large for Gestational Age Births}

Study

ID

$\operatorname{aOR}(95 \% \mathrm{Cl}) \quad$ Weight

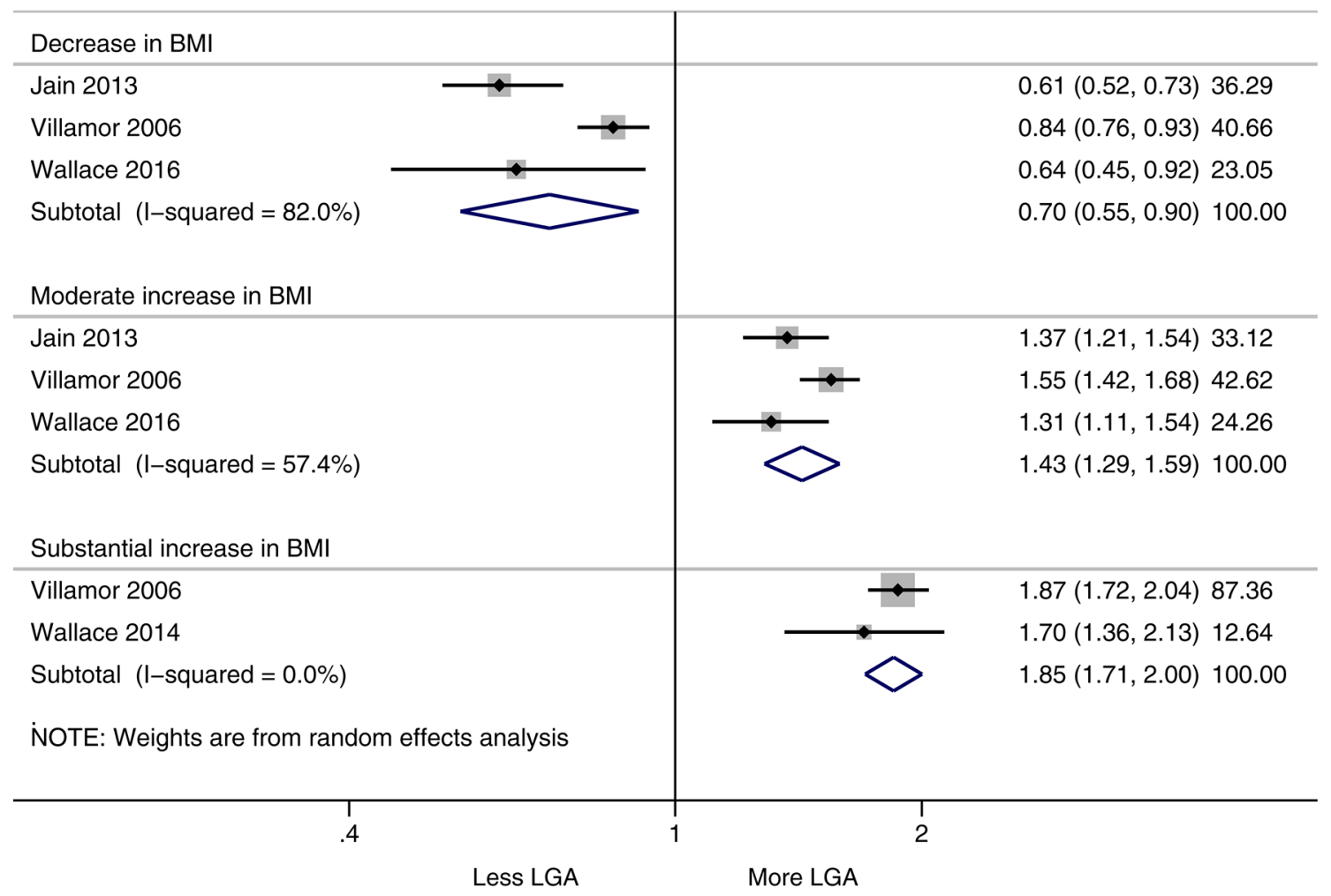

Figure 2 Forest plot showing change in interpregnancy weight and the risk of large-for-gestational-age (LGA) births in all women relative to reference category (decrease in body mass index (BMI) defined as $>-1$ unit, moderate increase 1-3 units and substantial increase $>3$ units, reference category remained in same BMI category or changed by up to -2 to +2 units). aOR, adjusted OR.

supplementary appendix 2, table 1 ) show that all three pooled estimates were statistically significant $(\mathrm{p}<0.05)$.

Only one study included macrosomia as an outcome. ${ }^{13}$ Their results showed that decrease in BMI had a reduced risk of macrosomia (aOR $0.5,95 \%$ CI 0.35 to 0.71 ), with a substantial increase in BMI associated with a higher risk of macrosomia (aOR 1.537, 95\% CI 0.939 to 2.505). It should be noted that this paper also reported data for low birth weight $(<2500 \mathrm{~g})$ and found that a decrease in BMI >-1 unit was associated with aOR 2.22 (95\% CI 1.41 to 3.51 ).

A decrease in BMI (>1 BMI unit) resulted in a decreased risk of GDM (aOR $0.80,95 \%$ CI 0.62 to $1.03, \mathrm{I}^{2}=51.1 \%$ ). A moderate increase in BMI was associated with a $56 \%$ increased risk of GDM (aOR $1.70,95 \%$ CI 1.48 to 1.96 , $\mathrm{I}^{2}=0.0 \%$ ). A substantial increase in BMI (>3 units) was similarly associated with a high risk of GDM (aOR 2.28, $95 \%$ CI 1.97 to $2.63, \mathrm{I}^{2}=0.0 \%$ ) (figure 3 ). $\mathrm{P}$ values for these pooled results were statistically significant for moderate $(\mathrm{p}<0.001)$ and substantial increase in BMI $(\mathrm{p}<0.001)$ and risk of GDM (see online supplementary appendix 2, table 1). $P$ values for decrease in BMI was not statistically significant $(\mathrm{p}>0.05)$.
No association was observed between a decrease in BMI and risk of CS births (aOR 0.97, 95\% CI 0.89 to $1.05, \mathrm{I}^{2}=0.0 \%$ ), while a moderate increase and substantial increase in BMI were associated with higher risks of CS (aOR 1.16, 95\% CI 1.06 to $1.26, \mathrm{I}^{2}=53.5 \%$ and aOR $1.72,95 \%$ CI 1.32 to $2.24, \mathrm{I}^{2}=89.1 \%$, respectively) (figure 4 ). Both moderate and substantial increase in BMI were statistically significant $(\mathrm{p}<0.05)$ (see online supplementary appendix 2, table 1$)$.

A decrease in BMI ( $>1$ BMI unit) was associated with an increase in SGA births (aOR 1.31, 95\% CI 1.06 to $1.63, \mathrm{I}^{2}=53.5 \%$ ), while an increase in BMI was associated with a decreased risk of SGA births compared with the reference category (aOR $0.83,95 \%$ CI 0.70 to 0.99 , $\mathrm{I}^{2}=56.8 \%$ ) (figure 5 ). Both these results are statistically significant (see online supplementary appendix 2, table $1)$.

\section{Outcomes grouped by BMI before first pregnancy}

Some studies divided women into women with a BMI of $<25 \mathrm{~kg} / \mathrm{m}^{2}$ at their first pregnancy (normal) and women with a BMI $>25 \mathrm{~kg} / \mathrm{m}^{2}$ at their first pregnancy (overweight/obese). 


\section{Gestational diabetes mellitus}

Study

ID

aOR $(95 \% \mathrm{Cl}) \quad$ Weight

\begin{tabular}{|c|c|c|}
\hline Decrease in BMI & & \\
\hline Ehrlich 2011 & & $0.61(0.42,0.90) 26.35$ \\
\hline Bogaerts 2013 & & $0.79(0.60,1.06) 35.82$ \\
\hline Villamor 2006 & & $0.98(0.75,1.28) 37.83$ \\
\hline Subtotal $(\mathrm{I}-$ squared $=51.1 \%)$ & & $0.80(0.62,1.03) 100.00$ \\
\hline \multicolumn{3}{|l|}{ Moderate increase in BMI } \\
\hline Ehrlich 2011 & $\rightarrow$ & $1.71(1.42,2.07) 56.34$ \\
\hline Villamor 2006 & $\longrightarrow$ & $1.67(1.32,2.11) 36.37$ \\
\hline Bogaerts 2013 & & $1.82(1.08,3.08) 7.29$ \\
\hline Subtotal $(\mathrm{I}-$ squared $=0.0 \%)$ & & $1.70(1.48,1.96) 100.00$ \\
\hline \multicolumn{3}{|l|}{ Substantial increase in BMI } \\
\hline Ehrlich 2011 & $\longrightarrow$ & $2.46(2.00,3.02) 49.24$ \\
\hline Villamor 2006 & $\rightarrow$ & $2.09(1.68,2.61) 43.09$ \\
\hline Bogaerts 2013 & 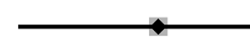 & $2.25(1.33,3.78) 7.67$ \\
\hline Subtotal $(\mathrm{I}-$ squared $=0.0 \%)$ & & $2.28(1.97,2.63) 100.00$ \\
\hline \multicolumn{3}{|l|}{ NOTE: Weights are from random effects analysis } \\
\hline \multirow[b]{2}{*}{ Less GDM } & & t \\
\hline & More GDM & \\
\hline
\end{tabular}

Figure 3 Forest plot showing change in interpregnancy weight and the risk of gestational diabetes mellitus (GDM) in all women relative to reference category (decrease in body mass index (BMI) defined as $>-1$ unit, moderate increase 1-3 units and substantial increase $>3$ units, reference category remained in same BMI category or changed by up to -2 to +2 units). aOR, adjusted OR.

Women of normal BMI $\left(<25 \mathrm{~kg} / \mathrm{m}^{2}\right)$ at beginning of first pregnancy are at a higher risk of LGA babies if they have a substantial increase of BMI (OR 2.10, 95\% CI 1.93 to $2.29, \mathrm{I}^{2}=7.7 \%$ ) compared with women who had an overweight/obese BMI $\left(\geq 25 \mathrm{~kg} / \mathrm{m}^{2}\right)$ at the beginning of first pregnancy (OR $1.69,95 \%$ CI 1.37 to $2.09, \mathrm{I}^{2}=86.2 \%$ ) (see online supplementary appendix 2, table 2 for statistical significance). The same trend is apparent in a moderate increase of BMI (an increase of between 1 and 3 units) (see online supplementary appendix 3 , figure 3-4).

Women of normal BMI $\left(<25 \mathrm{~kg} / \mathrm{m}^{2}\right)$ at beginning of first pregnancy are at a higher risk of GDM if they have a substantial increase of BMI (OR 3.10, 95\% CI 2.74 to $3.50, \mathrm{I}^{2}=0.0 \%$ ) compared with women who had an overweight/obese BMI $\left(\geq 25 \mathrm{~kg} / \mathrm{m}^{2}\right)$ at the beginning of first pregnancy (OR $1.82,95 \%$ CI 1.34 to $2.48, \mathrm{I}^{2}=51.6 \%$ ) (see online supplementary appendix 3, figure 3-4). The same trend is apparent in a moderate increase of BMI.

Women of normal BMI $\left(<25 \mathrm{~kg} / \mathrm{m}^{2}\right)$ at beginning of first pregnancy are at a higher risk of CS if they have a substantial increase of BMI (OR 1.70, 95\% CI 1.34 to $2.16, \mathrm{I}^{2}=87.7 \%$ ) compared with women who had an overweight/obese BMI ( $\left.\geq 25 \mathrm{~kg} / \mathrm{m}^{2}\right)$ at the beginning of first pregnancy (OR $1.52,95 \%$ CI 0.84 to $2.75, \mathrm{I}^{2}=78.0 \%$ ) (see online supplementary appendix 3 , figure 5-6). The same trend is apparent in a moderate increase of BMI. However, the CIs of these two ORs overlap and therefore the statistical significance can be questioned.

One study ${ }^{20}$ found that women of normal BMI $(<25 \mathrm{~kg} /$ $\mathrm{m}^{2}$ ) who lose weight during the interpregnancy interval are at a similarly strong risk of SGA (aOR 1.76, 95\% CI 1.35 to 2.28) compared with women of an overweight/ obese BMI $\left(>25 \mathrm{~kg} / \mathrm{m}^{2}\right.$ ) who lose weight (aOR $1.73,95 \%$ CI 1.18 to 2.54 ).

\section{Sensitivity analysis}

Sensitivity analysis was assessed by removing studies that had a high level of bias $(<3$ on the Cochrane analysis of bias) or were of low quality according to NOS ( $\leq 4$ stars). Removal of low-quality studies made limited difference to the results and the direction of effect remained the same. For LGA in women with a BMI $<25 \mathrm{~kg} / \mathrm{m}^{2}$, results before removal of studies included decrease in BMI (aOR 0.65, $95 \%$ CI 0.49 to $0.86, \mathrm{I}^{2}=79.9 \%$ ), moderate increase in 


\section{C-section}

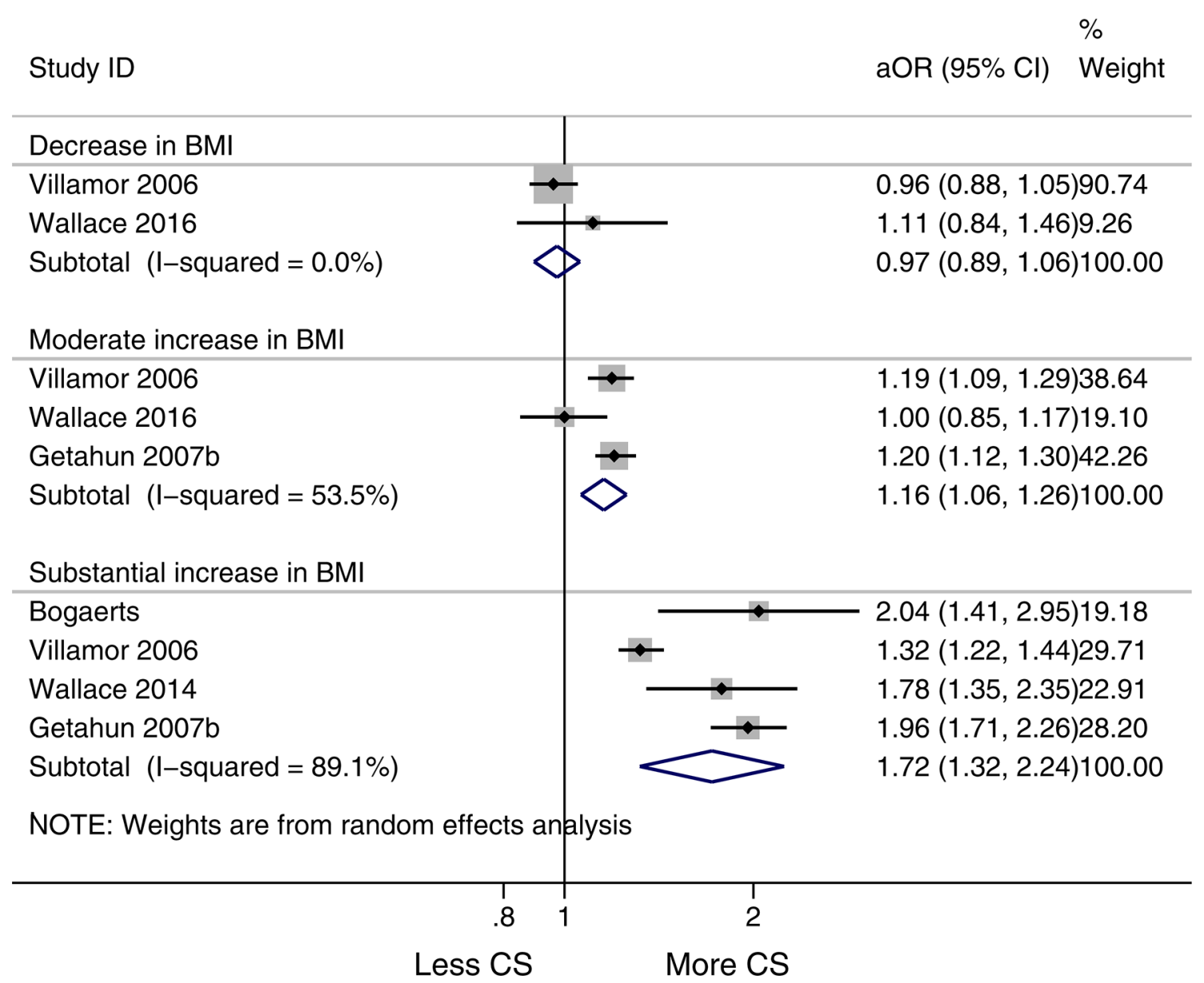

Figure 4 Forest plot showing change in interpregnancy weight and the risk of caesarean section (CS) in all women relative to reference category (decrease in body mass index (BMI) defined as $>-1$ unit, moderate increase 1-3 units and substantial increase $>3$ units, reference category remained in same BMI category or changed by up to -2 to +2 units). aOR, adjusted OR.

BMI (aOR $1.62,95 \%$ CI 1.54 to $1.71, \mathrm{I}^{2}=0 \%$ ) and substantial increase (aOR 2.10, 95\% CI 1.93 to $2.29, \mathrm{I}^{2}=7.7 \%$ ). After sensitivity analysis, heterogeneity for each of these groups decreased (see online supplementary appendix 4, table 1).

\section{Heterogeneity}

Generally, an $\mathrm{I}^{2}$ value of $25 \%$ is considered low, $50 \%$ moderate and $75 \%$ high. ${ }^{26}$ This value is thought to reflect the proportion of between-study variance not explained by sampling. When pooling results from population-based observational studies and the type of research used in this paper, it is impossible to control all possible confounders which is why a certain level of heterogeneity could be expected. As Higgins comments, if the predefined eligibility criteria and data are correct, any level of heterogeneity is acceptable, given that the authors can analyse the heterogeneous studies appropriately. ${ }^{27}$ Analysis in this paper included random-effects analysis and sensitivity analysis. Further analysis of heterogeneity in this review is warranted; however, the Cochrane handbook recommends that meta-regression should not be completed if there are fewer than 10 studies in a meta-analysis. ${ }^{28}$ Furthermore, it has been stated that this corresponds to 10 studies for each covariate in meta-regression. ${ }^{29}$ Due to this, the sources of heterogeneity will instead be discussed in limitations.

\section{DISCUSSION}

\section{Major findings}

This study found that an interpregnancy BMI decrease is associated with a reduced risk of LGA births (aOR 0.70, $95 \%$ CI 0.55 to $0.90, p<0001$ ), reduced risk of macrosomia (aOR $0.50,95 \%$ CI 0.35 to 0.71 ) and GDM (aOR 0.80, $95 \%$ CI 0.62 to 1.03 ) and an increased risk of SGA (aOR $1.31,95 \%$ CI 1.06 to $1.63, \mathrm{p}=0.01$ ) compared with reference category of women who retained BMI. A substantial increase in interpregnancy BMI (>3 BMI units) is associated with an increased risk of LGA (aOR 1.85, 95\% CI 1.71 to $2.00, \mathrm{p}<0.001$ ), GDM (aOR 2.28, 95\% CI 1.97 to 2.63, $\mathrm{p}<0.001$ ), CS (aOR $1.72,95 \%$ CI 1.32 to $2.24, \mathrm{p}<0.001)$ and macrosomia (aOR $1.54,95 \%$ CI 


\section{Small for Gestational Age}

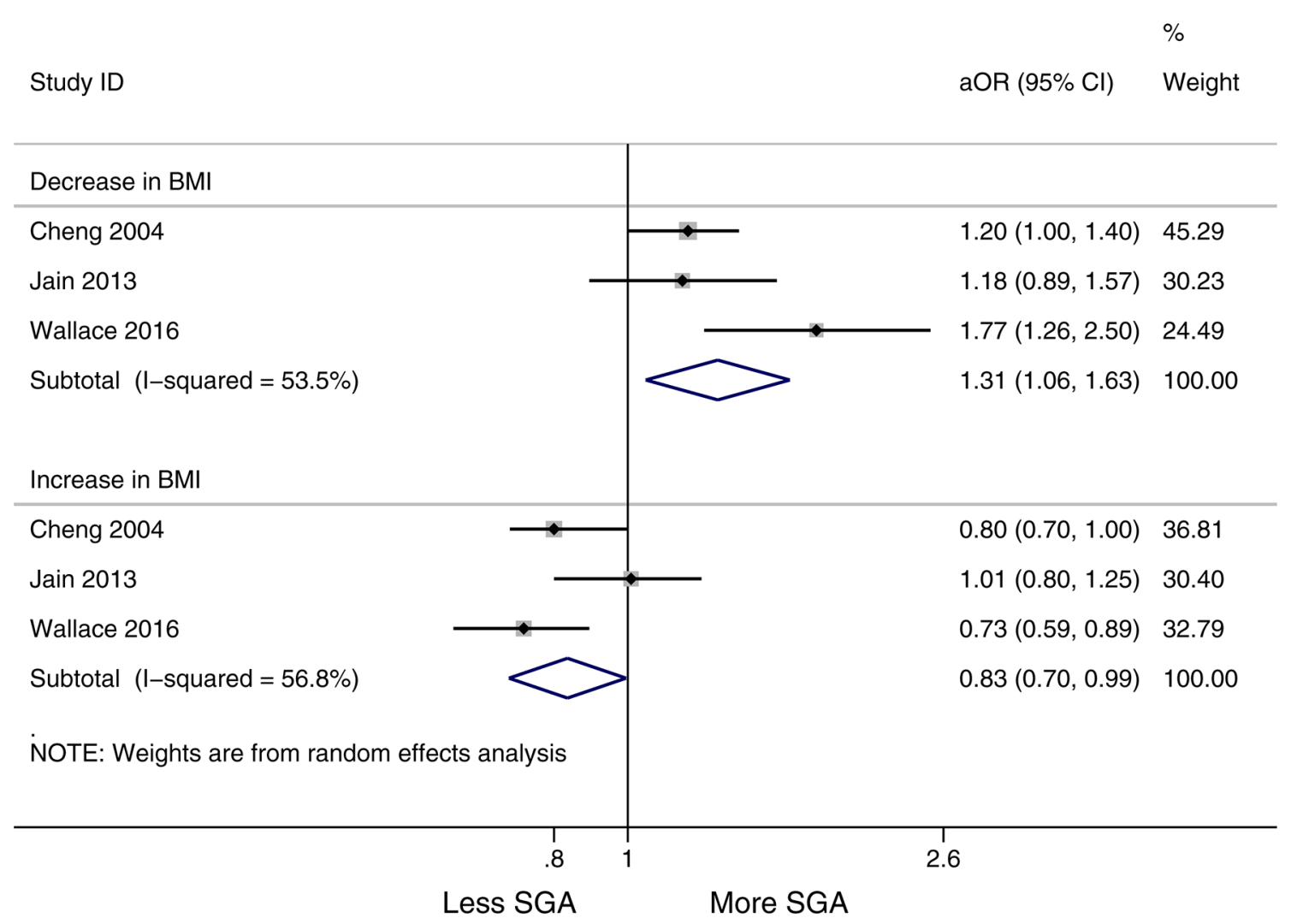

Figure 5 Forest plot showing change in interpregnancy weight and the risk of small-for-gestational-age (SGA) births in all women relative to reference category (decrease in body mass index (BMI) defined as $>-1$ unit, moderate increase 1-3 units and substantial increase $>3$ units, reference category remained in same BMl category or changed by up to -2 to +2 units). aOR, adjusted OR.

0.94 to 2.50) compared with the reference category (no weight change). An increase in BMI is associated with a decreased risk of SGA (aOR $0.83,95 \%$ CI 0.70 to 0.99 , $\mathrm{p}=0.044$ ). Results did not change after sensitivity analyses removing low quality and studies with high bias. We believe this is the first systematic review and meta-analysis completed on the topic of interpregnancy weight change and adverse pregnancy outcomes in women from parity 0 to 1 . When results are further analysed according to prepregnancy BMI $\left(<25 \mathrm{or}>25 \mathrm{~kg} / \mathrm{m}^{2}\right)$, women with a normal prepregnancy BMI at first pregnancy are at higher risk of LGA (aOR 2.10, 95\% CI 1.93 to 2.29) and GDM (aOR $3.10,95 \%$ CI 2.74 to 3.50 ) compared with women with a BMI $\geq 25 \mathrm{~kg} / \mathrm{m}^{2}$.

\section{Interpretation of major findings}

It is known that obesity is the most common risk factor for insulin insensitivity. ${ }^{30} \mathrm{~A}$ possible biological relation between obesity and adverse perinatal outcomes is the role of glucose and insulin insensitivity in pregnancy. The Pedersen Hypothesis, first suggested in 1952, stipulates that a higher-than-normal level of glucose (the main energy substrate of the fetus) transferred via the placenta to the fetus stimulates the release of insulin and insulin-like growth factors in the fetus, causing LGA infants or macrosomic births. ${ }^{31}$ This has been supported by research showing that high postprandial glucose concentration predicts large birth weight and hypoglycaemia is associated with growth restriction. ${ }^{32}$

An overweight or obese pregnant woman has a $50 \%-60 \%$ increase in insulin insensitivity compared with a normal weighted pregnant woman. ${ }^{33}$ Associated hyperglycaemia for the infant, as well as an increase in the release of free fatty acids and triglycerides from adipose stores have been studied to be associated with increased birth weight and adiposity of the offspring. ${ }^{34}$ The reduction in insulin sensitivity as a result of interpregnancy weight gain may lead to higher levels of GDM, LGA, macrosomia and subsequent CSs. On the contrary, weight loss and its association with increased insulin sensitivity may therefore result in reduced numbers of GDM and increased numbers of SGA births. This may be as increased insulin sensitivity may cause less glucose to cross the placenta and thus there is an increased risk of SGA. Studies researching interpregnancy weight change in women over three consecutive pregnancies support this finding, with weight loss associated with an increased risk of low placental weight and SGA births. ${ }^{35}$ Studies have found that not all interpregnancy weight gain is attributed to weight gain in 
pregnancy: $0.45 \mathrm{~kg}$ can be credited to the trend of weight gain over time.$^{36}$ Research has also shown that women with a BMI $\geq 25 \mathrm{~kg} / \mathrm{m}^{2}$ before pregnancy experience greater increases in postpartum body weight, and weight change 12 months post partum is largely influenced by the prepregnancy body weight. ${ }^{37}$ Interpregnancy weight gain as a result of both insufficient gestational weight loss after the previous pregnancy, combined with the normal trend of weight gain over time may have an additive or synergistic effect and result in further lowering of insulin sensitivity.

\section{Strengths}

We believe this is the first systematic review and meta-analysis completed on the topic of interpregnancy weight change and adverse pregnancy outcomes in women from parity 0 to 1 with singleton births. This review synthesised the available evidence on the association of interpregnancy weight change, defined as the difference in BMI in early pregnancy between successive pregnancies, on major complications. The findings of 11 cohort studies showed that interpregnancy weight gain was strongly associated with an increased risk of namely, GDM, CS and large birthweight babies among all women regardless of initial BMI status, and a decrease in risk of SGA. Conversely, interpregnancy weight loss was strongly associated with a reduced risk of GDM, and large birth eight in the secondborn offspring, an increase in risk of SGA, but no detectable association with the rate of CS. The criteria outlined in the PRISMA statement and the Cochrane Handbook for Systematic Reviews of Intervention was adhered to, and this can be seen in table 2 (see online supplementary appendix 4). Furthermore, the MOOSE checklist of recommendations for reporting meta-analyses of observational studies was followed. Results did not change even after sensitivity analyses of high methodological quality studies.

Studies included in this review were cohort studies with generally large sample sizes, resulting in a large pooled sample of almost 1 million women. The strengths of using these studies meant that they are population-based, with a generally representative population. Outcomes were classified in the same way in each study and for most of the outcomes it is objectively defined to classify if the outcome occurred or not, reducing a possible bias of assessment of outcome. In addition to this, the reliability of medical records has shown good level of both inter-rater and intrarater reliability. ${ }^{38}$ This review used two different ways of analysing the quality of studies and possible sources of bias-the NOS and the Cochrane analysis of bias. All studies had at least 4 stars on the NOS, and sensitivity analysis was performed to remove low-quality studies or studies with a high bias. All studies used aORs to adjust for confounding factors such as age, race, interpregnancy interval and previous adverse outcome in first pregnancy.

Parity and previous diabetes mellitus were adjusted for in this review, which included only primiparous women (from parity 0 to 1 ) with no previous history of type 2 diabetes mellitus (T2DM). Compared with low multiparity, primigravid women have different risks and complications while higher parity (parity 4 upwards) has been associated with increased obstetric complications and neonatal morbidity. ${ }^{39}$ Furthermore, T2DM during pregnancy is associated with higher risks of stillbirth, perinatal mortality and congenital malformations. ${ }^{40}$ Excluding these factors and taking into account that all papers included in this review were adjusted for multiple confounding variables means that it is less likely that the results are due to confounding or systematic bias and more likely to reflect genuine causality. Furthermore, this review aimed to minimise heterogeneity in several ways: each study was assessed to determine if confounding factors were appropriately recognised and adjusted for, weight change was stratified into three categories in order to effectively combine results that could be compared and sensitivity analysis was carried out by removing low-quality studies with a high level of bias.

\section{Limitations}

Originally in the search strategy and PROSPERO registration other outcomes were aimed to be included (preterm birth, pre-eclampsia, perinatal death); however, there was a lack of relevant data and low-quality studies linked to these outcomes and thus these outcomes were excluded from this report. Other deviations from the protocol included the population definition being expanded to all women and not just overweight/obese women, which enhances the external validity of the study. Subgroup analyses was not included in the registration as we did not have details of the analyses at the time of registration and this addition provide further nuance on our findings. Despite attempts to limit heterogeneity as described above, the high heterogeneity means that it may be misleading to combine results to provide an average estimate of exposure, especially in light of the relatively small sample sizes in each outcome. Conclusions should therefore be interpreted with caution and considered largely hypothesis-generating. The effect of confounders could not be assessed by comparing unadjusted ORs and aORs, as unadjusted data were not available nor was it possible to calculate based on the available data. A random-effects model was used rather than a fixed-effect model to assess heterogeneity in the meta-analysis as it considers in-between study variation. Further statistical analysis to assess heterogeneity such as meta-regression was not performed due to the limited number of studies for each outcome; however, possible sources of heterogeneity are listed in table 4. Many of the studies report missing data and have categorised BMI change differently (eg, units, WHO groups or percentages), making it difficult to combine data in a meaningful and objective way. However, this was addressed with subgroup analysis and by stratifying weight change into categories. The use of observational cohort studies means that it is very difficult to adjust for all possible confounding factors, leading to an inevitable heterogeneity between studies. Publication bias 


\begin{tabular}{ll}
$\begin{array}{l}\text { Table } 4 \text { Possible reasons to explain high heterogeneity }\left(\mathrm{I}^{2}\right) \\
\text { found in the review }\end{array}$ \\
$\begin{array}{l}\text { Possible sources of } \\
\text { heterogeneity }\end{array}$ & Example \\
\hline $\begin{array}{l}\text { Classification of body mass } \\
\text { index change }\end{array}$ & $\begin{array}{l}\text { Units }\left(\mathrm{kg} / \mathrm{m}^{2}\right), \text { WHO groups } \\
\text { (underweight, obese) }\end{array}$ \\
\hline Different population design & $\begin{array}{l}\text { Sources of data varied, } \\
\text { locations of studies varied }\end{array}$ \\
\hline Differences in study design & $\begin{array}{l}\text { Use of self-report for height } \\
\text { and weight }\end{array}$ \\
\hline Missing data & $\begin{array}{l}\text { Missing data in original } \\
\text { studies could not be } \\
\text { controlled for }\end{array}$ \\
\hline $\begin{array}{l}\text { Small number of studies for } \\
\text { each outcome }\end{array}$ & $\begin{array}{l}\text { Between two and five studies } \\
\text { for each outcome }\end{array}$ \\
$\begin{array}{l}\text { Unknown factors (residual } \\
\text { confounding variables) }\end{array}$ & $\begin{array}{l}\text { Breast feeding, family history, } \\
\text { diet, exercise }\end{array}$ \\
\hline
\end{tabular}

could not be assessed due to the small amount of studies in each primary outcome, with most of the outcomes having between two and five studies in each category. It has been suggested that $<10$ studies is not adequate in order to complete a funnel plot and would thus be underpowered. ${ }^{41}$

BMI is closely linked to lifestyle factors, diseases and genetic traits that are correlated with the outcome of pregnancy. Although studies adjusted for multiple confounding factors, there are additional confounders that could affect results that were not adjusted for, including breast feeding, diet, exercise and genetics. In addition, the effect of obesity may be confounded by several comorbidities that are possibly undiagnosed. Breast feeding may be a possible confounding factor in interpregnancy weight change as women who breast feed have less weight post partum, which is thought to be due to the high calorie usage during breast feeding, however this is contentious. ${ }^{42}$ The lack of information regarding diet and exercise means that the reduced risk of adverse outcomes in pregnancy may not be due to the weight loss but due to other aspects that are changed in a healthier lifestyle. Furthermore, interpregnancy interval and gestational weight gain were adjusted for in some studies, but the effect of these should not be underestimated. The shorter the interpregnancy interval, the higher the risk of LGA. ${ }^{43}$ The shorter the time between pregnancies or the more gestational weight gain, the more difficult it may be for women to lose the weight gained from the previous pregnancy. All future studies should adjust for interpregnancy interval. Gestational weight gain is responsible for interpregnancy weight gain after the first pregnancy, but is a potential mediator in the second pregnancy and therefore it is questionable whether it should be adjusted for.

This review focused on singleton births from parity 0 to 1 , with all of the studies coming from high-income Western countries. This limits the generalisability of the conclusions to lower-income countries. Even though this review did exclude women with previous T2DM, it should be noted that due to the lack of a universal screening for GDM, some women with GDM may have been missed. This is difficult to assess and control, and due to the controversy surrounding screening for GDM and the lack of good quality evidence-based data, it has been unable to determine whether or not screening would have an important effect on adverse pregnancy outcomes. ${ }^{44}$

\section{Future research}

This review highlights that observational studies can help give direction for future research. To help clarify the association between interpregnancy weight change and adverse pregnancy outcomes, a precise way of measuring BMI change needs to be implemented and subgroup definitions should be consistent. Due to the problems with low rate of outcome, large studies free of bias associated with recall and self-report need to be undertaken that adhere to STrenghtening the Reporting of OBservational studies in Epidemiology (STROBE) guidelines and International Consortium for Health Outcomes Measurement (ICHOM) standards. Future researchers should also consider the possible synergistic and additive effect of normal weight gain over time combined with insufficient postpartum weight loss and how it can affect pregnancy outcomes.

Large-scale studies on specific classes of obesity should be conducted to study the rate of weight change and if it affects the magnitude of association. The National Institute for Health Research submitted a call for research regarding weight management after pregnancy, stating that excessive gestational weight gain or postpartum weight retention may be cumulative over successive pregnancies. ${ }^{45}$ The Supporting Women with Postnatal Management feasibility study is aiming to study women allocated to an intervention (weight management group) or control group at 36 weeks of pregnancy and followed up 12 months postnatally. This will be one of the first studies to look at postnatal intervention in weight control in the UK. ${ }^{46}$ Furthermore, Slimming World undertook a study in Cardiff called Health Eating and Lifestyle in Pregnancy to look at the benefits of behaviour changes and weight management during pregnancy in the UK. The study was underpowered but healthy eating and lifestyle intervention was acceptable to help women control their weight change during pregnancy and post partum. ${ }^{47}$ Other feasibility studies such as Pregnancy and Weight Monitoring are currently underway and evaluation of the efficacy of these interventions is expected in the future. ${ }^{48}$

\section{Implications for policy makers and clinicians}

The NICE postnatal guidelines currently suggest that women with a BMI $>30 \mathrm{~kg} / \mathrm{m}^{2}$ at the $6-8$ weeks postnatal check are referred for advice regarding weight loss. This review provides some evidence to suggest that postnatal weight interventions are needed, as even moderate changes in interpregnancy BMI can lead to increased 
risks of adverse pregnancy outcomes for the mother and baby. However, the effect of weight loss on increased risk of SGA should not be forgotten.

The Institute of Medicine has introduced optimal weight gain for BMI-specific ranges in pregnancy, although NICE has recommended that these guidelines should be researched to see if they are appropriate for the UK population. ${ }^{49}$ Based on the results of this review, it can be suggested that clinicians should be aware of the risk in women whose BMI has changed after their first pregnancy. Particularly women who wish to conceive again shortly after birth of their first child should be monitored after pregnancy to attempt to keep BMI change to a minimum. Importantly, women who are at a healthy weight are not without risk. Therefore, monitoring gestational weight change is important in preventing adverse outcomes in pregnancy, and interpregnancy weight change can also influence maternal and fetal outcomes.

\section{CONCLUSION}

This study is the first systematic review and meta-analysis to assess the association of interpregnancy weight change on five adverse pregnancy outcomes. The results show that interpregnancy weight gain increases the risk of GDM, CS and LGA, but lowers the risk of SGA, while weight reduction lowers the risk of GDM and LGA and increases the risk of SGA. In particular, it is noted that weight gain from normal weight is more detrimental than from a higher weight in regard to GDM, LGA and CS. Keeping weight stable between consecutive conceptions is important in order to lower the risk of adverse pregnancy outcomes. However, further research is needed to substantiate the evidence presented in this review.

Acknowledgements The authors would like to thank all reviewers for their helpful comments.

Contributors EO-N formulated the research question and wrote and reviewed the report. SM did the literature search, extracted and selected articles, completed the meta-analysis and wrote the report. OS did the literature search, extracted and selected articles and contributed to writing the paper. PTS completed the metaanalysis. DB and LP contributed to the writing of the paper.

Funding EO-N is partly funded by the Big Lottery Fund, NIHR, Tommy's Charity and Guy's and St Thomas' Charity. LP is partly funded by Tommy's Charity. PTS is partly funded by CLAHRC South London (NIHR) and Tommy's Charity.

Competing interests None declared.

Patient consent Not required.

Provenance and peer review Not commissioned; externally peer reviewed.

Data sharing statement No additional data are available.

Open Access This is an Open Access article distributed in accordance with the Creative Commons Attribution Non Commercial (CC BY-NC 4.0) license, which permits others to distribute, remix, adapt, build upon this work non-commercially, and license their derivative works on different terms, provided the original work is properly cited and the use is non-commercial. See: http://creativecommons.org/ licenses/by-nc/4.0/

(C) Article author(s) (or their employer(s) unless otherwise stated in the text of the article) 2018. All rights reserved. No commercial use is permitted unless otherwise expressly granted.
REFERENCES

1. Yu Z, Han S, Zhu J, et al. Pre-pregnancy body mass index in relation to infant birth weight and offspring overweight/obesity: a systematic review and meta-analysis. PLoS One 2013;8:e61627.

2. Chu SY, Kim SY, Lau J, et al. Maternal obesity and risk of stillbirth: a metaanalysis. Am J Obstet Gynecol 2007;197:223-8.

3. Jovanovič L, Liang Y, Weng W, et al. Trends in the incidence of diabetes, its clinical sequelae, and associated costs in pregnancy. Diabetes Metab Res Rev 2015;31:707-16.

4. Balen AH, Anderson RA. Policy \& Practice Committee of the BFS. Impact of obesity on female reproductive health: British Fertility Society, Policy and Practice Guidelines. Hum Fertil 2007;10:195-206.

5. Leddy MA, Power ML, Schulkin J. The impact of maternal obesity on maternal and fetal health. Rev Obstet Gynecol 2008;1:170-8.

6. Oteng-Ntim E, Varma R, Croker $\mathrm{H}$, et al. Lifestyle interventions for overweight and obese pregnant women to improve pregnancy outcome: systematic review and meta-analysis. BMC Med 2012;10:47.

7. Johnson K, Posner SF, Biermann J, et al. Recommendations to improve preconception health and health care--United States. A report of the CDC/ATSDR Preconception care work group and the select panel on preconception care. MMWR Recomm Rep 2006;55:1-22.

8. Whitworth M, Dowswell T. Routine pre-pregnancy health promotion for improving pregnancy outcomes. Cochrane Database Syst Rev 2009;4:CD007536.

9. Tieu J, Bain E, Middleton P, et al. Interconception care for women with a history of gestational diabetes for improving maternal and infant outcomes. Cochrane Database Syst Rev 2013;6:CD010211.

10. PROSPERO. International prospective register of systematic reviews. York: Centre for Reviews and Dissemination. (accessed 22 Jun 2016).

11. Cnattingius S, Villamor E. Weight change between successive pregnancies and risks of stillbirth and infant mortality: a nationwide cohort study. Lancet 2016;387:558-65.

12. World Health Organisation. Body mass index (BMI) classification. 2016. www. who.int/bmi/index.jsp?introPage=intro_3.html (accessed 04 Feb 2017).

13. Bogaerts A, Van den Bergh BR, Ameye L, et al. Interpregnancy weight change and risk for adverse perinatal outcome. Obstet Gynecol 2013;122:999-1009.

14. Cheng CJ, Bommarito K, Noguchi A, et al. Body mass index change between pregnancies and small for gestational age births. Obstet Gynecol 2004;104:286-92.

15. Ehrlich SF, Hedderson MM, Feng J, et al. Change in body mass index between pregnancies and the risk of gestational diabetes in a second pregnancy. Obstetrics \& Gynecology 2011;117:1323-30.

16. Getahun D, Ananth CV, Peltier MR, et al. Changes in prepregnancy body mass index between the first and second pregnancies and risk of large-for-gestational-age birth. Am J Obstet Gynecol 2007;196:530.e1-8.

17. Getahun D, Ananth CV, Oyelese Y, et al. Primary preeclampsia in the second pregnancy: effects of changes in prepregnancy body mass index between pregnancies. Obstet Gynecol 2007;110:1319-25.

18. Jain AP, Gavard JA, Rice JJ, et al. The impact of interpregnancy weight change on birthweight in obese women. Am J Obstet Gynecol 2013;208:205.e1-7.

19. Whiteman VE, Mclntosh C, Rao K, et al. Interpregnancy BMI change and risk of primary caesarean delivery. J Obstet Gynaecol 2011;31:589-93.

20. Whiteman VE, Aliyu MH, August EM, et al. Changes in prepregnancy body mass index between pregnancies and risk of gestational and type 2 diabetes. Arch Gynecol Obstet 2011;284:235-40.

21. Wallace JM, Bhattacharya S, Campbell DM, et al. Inter-pregnancy weight change impacts placental weight and is associated with the risk of adverse pregnancy outcomes in the second pregnancy. BMC Pregnancy Childbirth 2014;14:40.

22. Wallace JM, Bhattacharya S, Campbell DM, et al. Inter-pregnancy weight change and the risk of recurrent pregnancy complications. PLoS One 2016;11:e0154812.

23. Villamor E, Cnattingius S. Interpregnancy weight change and risk of adverse pregnancy outcomes: a population-based study. Lancet 2006;368:1164-70.

24. Wells G, Shea B, O'Connell J, et al. The Newcastle-Ottawa Scale (NOS) for assessing the quality of nonrandomised studies in metaanalysis. 2011. https://www.ohri.ca/programs/clinical_epidemiology/ oxford.asp (accessed 28 Feb 2017)

25. Higgins JP, Altman DG, Gøtzsche PC, et al. The Cochrane Collaboration's tool for assessing risk of bias in randomised trials. BMJ 2011;343:d5928. 
26. Higgins JP, Thompson SG, Deeks JJ, et al. Measuring inconsistency in meta-analyses. BMJ 2003;327:557-60.

27. Higgins JP. Commentary: Heterogeneity in meta-analysis should be expected and appropriately quantified. Int $J$ Epidemiol 2008;37:1158-60.

28. Higgins JPT, Altman DG, Sterne JAC. Chapter 9: Meta-regression. In: Higgins JPT, Green S, eds. Cochrane Handbook for Systematic Reviews of Interventions Version 5.1.0: The Cochrane Collaboration, 2011. (accessed 14 Mar 2017).

29. Borenstein ML, Hedges V, Higgins JPT, et al. Chapter 20: Metaregression. Introduction to meta-analysis. Chichester: John Wiley \& Sons Ltd, 2009.

30. Catalano PM. Obesity, insulin resistance, and pregnancy outcome. Reproduction 2010;140:365-71.

31. Pedersen J. Diabetes and pregnancy: blood sugar of newborn infants. Copenhagen, Denmark: Danish Science Press, 1952.

32. Scholl TO, Sowers M, Chen X, et al. Maternal glucose concentration influences fetal growth, gestation, and pregnancy complications. Am J Epidemiol 2001;154:514-20.

33. Catalano PM, Hauguel-De Mouzon S. Is it time to revisit the Pedersen hypothesis in the face of the obesity epidemic? Am J Obstet Gynecol 2011;204:479-87.

34. Di Cianni G, Miccoli R, Volpe L, et al. Maternal triglyceride levels and newborn weight in pregnant women with normal glucose tolerance. Diabet Med 2005;22:21-5.

35. Wallace JM, Bhattacharya S, Horgan GW. Weight change across the start of three consecutive pregnancies and the risk of maternal morbidity and SGA birth at the second and third pregnancy. PLoS One 2017;12:e0179589.

36. Greene GW, Smiciklas-Wright H, Scholl TO, et al. Postpartum weight change: how much of the weight gained in pregnancy will be lost after delivery? Obstet Gynecol 1988;71:701-7.

37. McKEOWN T, Record RG. The influence of weight and height on weight changes associated with pregnancy in women. $J$ Endocrinol 1957;15:423-9.

38. Ock M, Lee SI, Jo MW, et al. Assessing reliability of medical record reviews for the detection of hospital adverse events. J Prev Med Public Health 2015;48:239-48.
39. Bai J, Wong FWS, Bauman A, et al. Parity and pregnancy outcomes. Am J Obstet Gynecol 2002;186:274-8.

40. Ray JG, Vermeulen MJ, Shapiro JL, Kenshole AB. Maternal and neonatal outcomes in pregestational and gestational diabetes mellitus, and the influence of maternal obesity and weight gain: the DEPOSIT study. QJM 2001;94:347-56.

41. Lau J, loannidis JP, Terrin N, et al. The case of the misleading funnel plot. BMJ 2006;333:597-600.

42. Allen J, Hector D. Benefits of breastfeeding. : N S W Public Health Bull, 2005:16: 42-6.

43. Zhu BP. Effect of interpregnancy interval on birth outcomes: findings from three recent US studies. Int $J$ Gynaecol Obstet 2005;89:S25-33.

44. Brody SC, Harris R, Lohr K. Screening for gestational diabetes: a summary of the evidence for the U.S. Preventive Services Task Force. Obstet Gynecol 2003;101:380-92.

45. National Institute of Health Research. 14/67 Weight management after pregnancy. 2014. njl-admin.nihr.ac.uk/document/download/ 2007433 (accessed 14 Mar 2017).

46. IRAS. Supporting Women with Postnatal Weight MAnagemeNt - SWAN Feasibility Trial Protocol. 2016. njl-admin.nihr.ac.uk/ document/download/2007612 (accessed 14 Mar 2017).

47. Jewell K, Avery A, Barber J, et al. The healthy eating and lifestyle in pregnancy (HELP) feasibility study. Br J Midwifery 2014;22:727-36.

48. Sanders J. Pregnancy and weight monitoring (PRAM). 2016 (accessed 14 Mar 2017).

49. National Institute for Health and Care Excellence. Weight management before, during and after pregnancy: Public health guideline. 2010 (accessed 14 Mar 2017).

50. Najafian M, Cheraghi M. Occurrence of fetal macrosomia rate and its maternal and neonatal complications: a 5-year cohort study. ISRN Obstet Gynecol 2012;2012:1-5.

51. Centre for Maternal and Child Enquiries. Maternal obesity in the UK: findings from a national project. London: CMACE, 2010.

52. American Diabetes Association. Gestational diabetes mellitus. Diabetes Care 2004;27:88-90. 